\title{
KINETICS OF BORAX DEHYDRATION BY THERMAL ANALYSIS
}

\author{
Elif AKBAY 1, *, Mehmet R. ALTIOKKA ${ }^{1}$ \\ ${ }^{1}$ Department of Chemical Engineering, Faculty of Engineering, Anadolu University, 26470, Eskişehir, Turkey
}

\begin{abstract}
Anhydrous borax is an important industrial product obtained either from borax decahydrate or borax pentahydrate. The kinetics of dehydration of borax pentahydrate using TG and DTA techniques was studied. It was shown that 2.25 mole of the crystal water removes in the first step with zero order kinetics in the temperature range between 382 and $433 \mathrm{~K}$. The removing of the remaining water was completed at $733 \mathrm{~K}$ with the second order reaction in the second steps. Arrhenius form of reaction rate constant for step 1 and 2 were also determined. They are: $k_{0}=5.37 \times 10^{15} \exp (-16141.5 / T)$ and $k_{2}=1.4 \exp (-1575.6 / T)$ respectively, where $\mathrm{T}$ is absolute temperature in $\mathrm{K}$.
\end{abstract}

The total activation energy calculated from Coats-Redfern method was found to be $147.3 \mathrm{~kJ} / \mathrm{mol}$. It was also found that this value is in a good agreement with those calculated from Kissinger and Doyle methods.

Keywords: Dehydration, Non-isothermal kinetic, Borax, Thermal Analysis

\section{INTRODUCTION}

Borax, also known as sodium borate, sodium tetraborate, or disodium tetraborate, is an important boron compound, a mineral, and a salt of boric acid. Usually a white powder consisting of soft colorless crystals dissolves easily in water.

Anhydrous borax, $\mathrm{Na}_{2} \mathrm{~B}_{4} \mathrm{O}_{7}$, is an industrial product produced from borax decahydrate $\left(\mathrm{Na}_{2} \mathrm{~B}_{4} \mathrm{O}_{7} .10 \mathrm{H}_{2} \mathrm{O}\right)$ and borax pentahydrate $\left(\mathrm{Na}_{2} \mathrm{~B}_{4} \mathrm{O}_{7} .5 \mathrm{H}_{2} \mathrm{O}\right)$. It is used as a flux material in metallurgy, and in the production of high quality glasses [1], ceramic materials [2] and enamels [3]. Also borax is used as raw material for producing $\mathrm{NaBH}_{4}$ as a hydrogen storage material [4]. Anhydrous borax is preferred to other hydrated borax salts in high temperature applications since it does not cause any foaming problems originating from dehydration of the water of crystallization [5].

The borate ion in the borax structure has the chemical formula of $\mathrm{B}_{4} \mathrm{O}_{5}(\mathrm{OH})_{4}^{-2}$. Borax decahydrate and pentahydrate are $\mathrm{Na}_{2}\left(\mathrm{~B}_{4} \mathrm{O}_{5}(\mathrm{OH})_{4}\right) \cdot 8 \mathrm{H}_{2} 0$ and $\mathrm{Na}_{2}\left(\mathrm{~B}_{4} \mathrm{O}_{5}(\mathrm{OH})_{4}\right) \cdot 3 \mathrm{H}_{2} \mathrm{O}$, respectively. In both of these hydrates, 2 molecules of water are structurally incorporated in the borate ion as hydroxyl groups. The remaining water molecules are outside the ionic structure. Removal of the water molecules of crystallization is relatively easy whereas the removal of water molecules in ionic structure is difficult [6].

The kinetics of dehydration of mineral using thermal analysis devices (thermogravimetry, TG and differential thermal analysis, DTA) has been commonly investigated utilizing various theoretical methods [7-11]. In such a work, the dehydration kinetics of tincal and borax decahydrate was investigated by TG and DTA. Applying different methods such as Coats and Redfern, Kissinger, Doyle and McCarty methods, to the experimental data, activation energy and frequency factor in Arrhenius equation were calculated. The results obtained from each method were reported to be compatible [12].

Also some technical methods proposed for borax dehydration are available in literature. In one of these works, the production of anhydrous borax from borax pentahydrate in a prototype furnace was 
studied without referring to the kinetic behavior of dehydration [13]. In another work in this concept, the anhydrous borax process in a fluidized bed calcinator was optimized with genetic algorithm method. It was claimed that the basic feature of the dehydration of borax pentahydrate to anhydrous borax is concerned with the conditions employed [5].

Although many other works on the dehydration of borax have been reported $[14,15]$, it is noticed that the kinetics relating to the production of anhydrous borax from borax pentahydrate is not thoroughly studied. Thus, the objective of this work is to determine the kinetic parameters of the dehydration of borax pentahydrate by using TG and DTA techniques.

\section{EXPERIMENTAL}

The borax pentahydrate, BPH used for experimental studies was obtained from Etibank, Kirka Plant, in Turkey. The chemical analysis of sample is given in Table 1. The average particle size, measured with Malvern Hydro 2000G device, is about $100 \mu \mathrm{m}$. It is assume that temperature distribution within the particle is uniform due to a rapid penetration of heat into the particle whose size is less than $100 \mu \mathrm{m}$.

Table 1. Chemical analysis of BPH

\begin{tabular}{cc}
\hline $\mathrm{B}_{2} \mathrm{O}_{3}(\%)$ & 48 \\
$\mathrm{Na}_{2} \mathrm{O}(\%)$ & 21.37 \\
$\mathrm{SO}_{4}(\mathrm{ppm})$ & 100 \\
$\mathrm{Cl}(\mathrm{ppm})$ & 50 \\
$\mathrm{Fe}(\mathrm{ppm})$ & 2.50 \\
Insoluble (ppm) & 115 \\
\hline
\end{tabular}

Netzsch STA 409 PG model Thermal Analyzer was used for thermal analysis of borax samples. Approximately $50 \mathrm{mg}$ of sample was loaded into an alumina crucible for each experiment. TG and DTA tests were performed at $40 \mathrm{~mL} \cdot \mathrm{min}^{-1}$ of nitrogen flow and 1,5 and $10 \mathrm{~K} \cdot \mathrm{min}^{-1}$ heating rates. TG and DTA curves for BPH at various heating rates are presented in Figures 1 and 2 respectively.

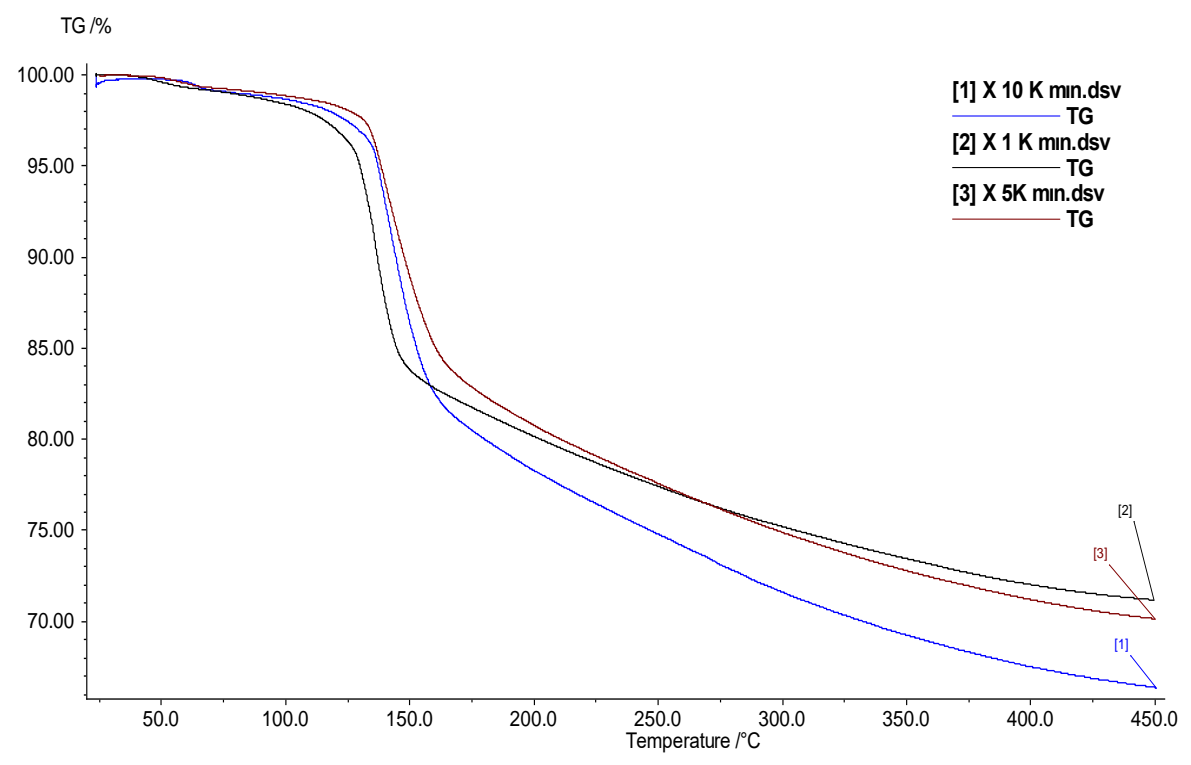

Figure 1. TG curves for BPH at different heating rates 


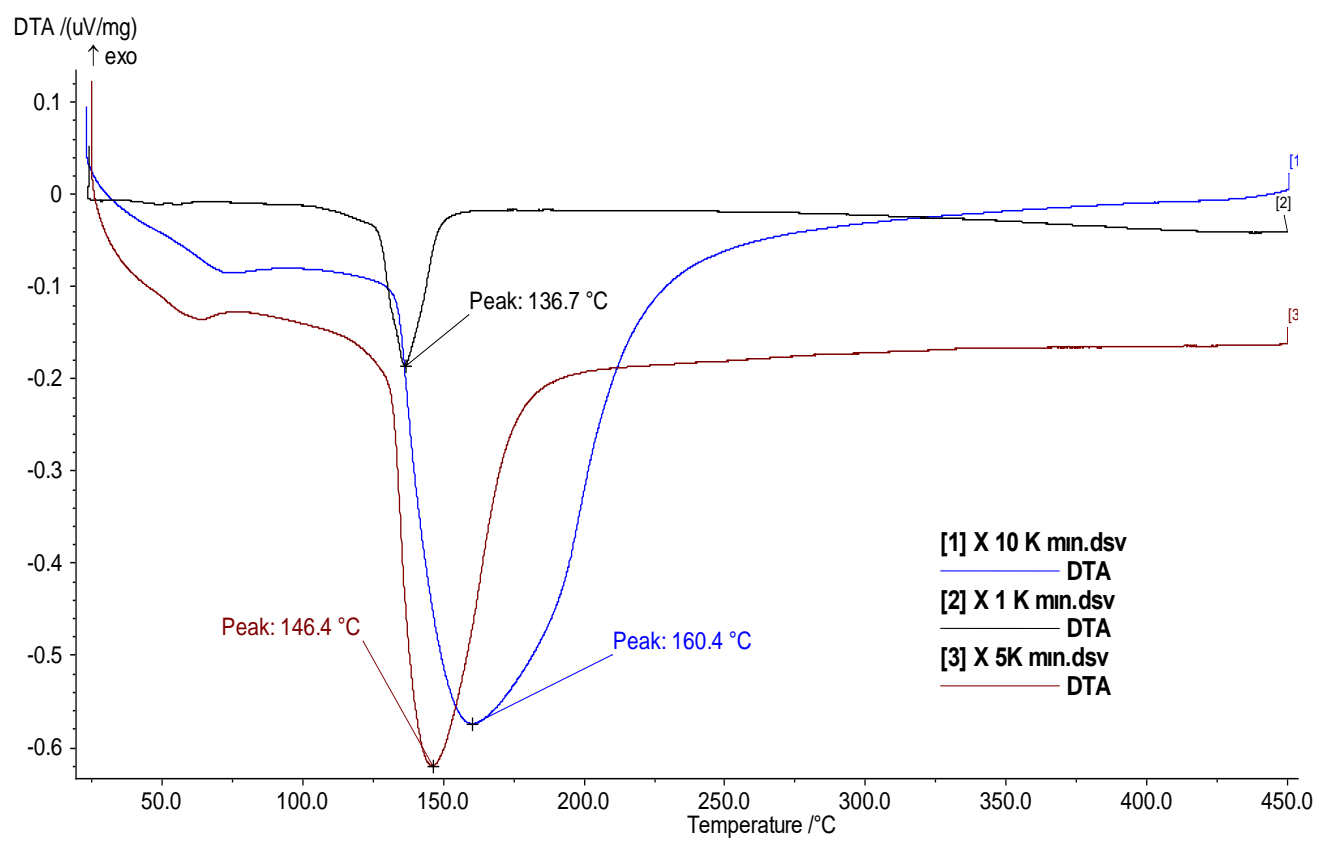

Figure 2. DTA curves for BPH at various heating rates

\section{RESULTS AND DISCUSSION}

Various theoretical methods for kinetic analysis have been reported in the literature [16-18]. The methods used in the present work are briefly described below. Kinetics expression, for the reaction,

$$
\text { solid } \rightarrow \text { solid + gas }
$$

may be described by the following equation:

$$
\begin{gathered}
\frac{d x}{d t}=k_{0}(1-x)^{n} \exp (-E / R T) \\
T=T_{0}+\beta t
\end{gathered}
$$

In thermal analysis, time is related to the temperature by the Eq. 2. The values given in Eq.2 can be substituted into Eq 1. If the integrated form of Eq. 1, after neglecting the term $2 R T / E$, which is much smaller than unity, rearranged, the following equations are obtained [18].

$$
\begin{gathered}
\text { For } n=1: \ln \left[\frac{-\ln (1-x)}{T^{2}}\right]=\ln \frac{k_{0} R}{\beta E}-\frac{E}{R T} \\
\text { For } n \neq 1: \ln \left[\frac{1-(1-x)^{1-n}}{T^{2}(1-n)}\right]=\ln \frac{k_{0} R}{\beta E}-\frac{E}{R T}
\end{gathered}
$$


The plot of left hand side in these equations versus $1 / \mathrm{T}$ will give a straight line. Frequency factor, $\mathrm{k}_{0}$ and activation energy, E, can be obtained from the intersection and slope of these lines. Application of these equations to the experimental data is known as the Coats and Redfern method.

To utilize DTA data, Kissinger [19] pointed out that the reaction rate, $\mathrm{d} x / \mathrm{d} t$, gradually increases to a maximum value as temperature rises and then decreases to zero as the reactant is depleted. Therefore the maximum reaction rate is reached when $\mathrm{d} / \mathrm{d} t(\mathrm{~d} x / \mathrm{d} t)$ is zero. By differentiating Eq. 1 and setting it to zero the following equation is obtained:

$$
\ln \left(\frac{\beta}{T_{m}^{2}}\right)=\ln \frac{k_{0} R}{E}-\frac{E}{R T_{m}}
$$

Application of Eq. 4 to the DTA data, at different heating rate, results a straight line. Frequency factor, $\mathrm{k} 0$ and activation energy, E, can be obtained from the intersection and slope of this line.

The other approximating method, based on DTA data, is proposed by Doyle [20]. It is given as follows.

$$
\begin{aligned}
& \frac{d(\log \beta)}{d\left(1 / T_{m}\right)} \approx 0.457 \frac{E}{R} \\
& k_{0}=\frac{\beta E}{R T_{m}^{2}} \exp \left(\frac{E}{R T_{m}}\right)
\end{aligned}
$$

Activation energy, $\mathrm{E}$ and frequency factor, $\mathrm{k}_{0}$ can be calculated from Eqs. $5 \mathrm{a}$ and $5 \mathrm{~b}$ respectively.

Although the method of Coats and Redfern requires detailed calculations, the calculations can be carried out only with the use of a single TG curve. The net advantage of this method is the determination of the reaction order and steps, simultaneously. The rest of the methods (Kissinger, and Doyle) used in this work utilize DTA peak temperatures obtained at various heating rates. In deriving the theory of these methods, the reaction order does not appear in the equations. Thus, the reaction order cannot be determined by these methods.

\subsection{Kinetics Modeling}

As seen from TG curve in Figure 1, the dehydration starts approximately at $380 \mathrm{~K}$ and completes at about $723 \mathrm{~K}$. The dehydration patterns, shown in DTA curve in Figure 2, under different heating rates were similar except for the slight increment in the peak temperatures with increasing heating rate.

Eqs. 3s were applied to the TG data obtained at $5 \mathrm{~K} \cdot \mathrm{min}^{-1}$ and resulting curves, for different reaction order, $\mathrm{n}$ is shown in Figure 3. At the other heating rate, similar curves were also observed. 


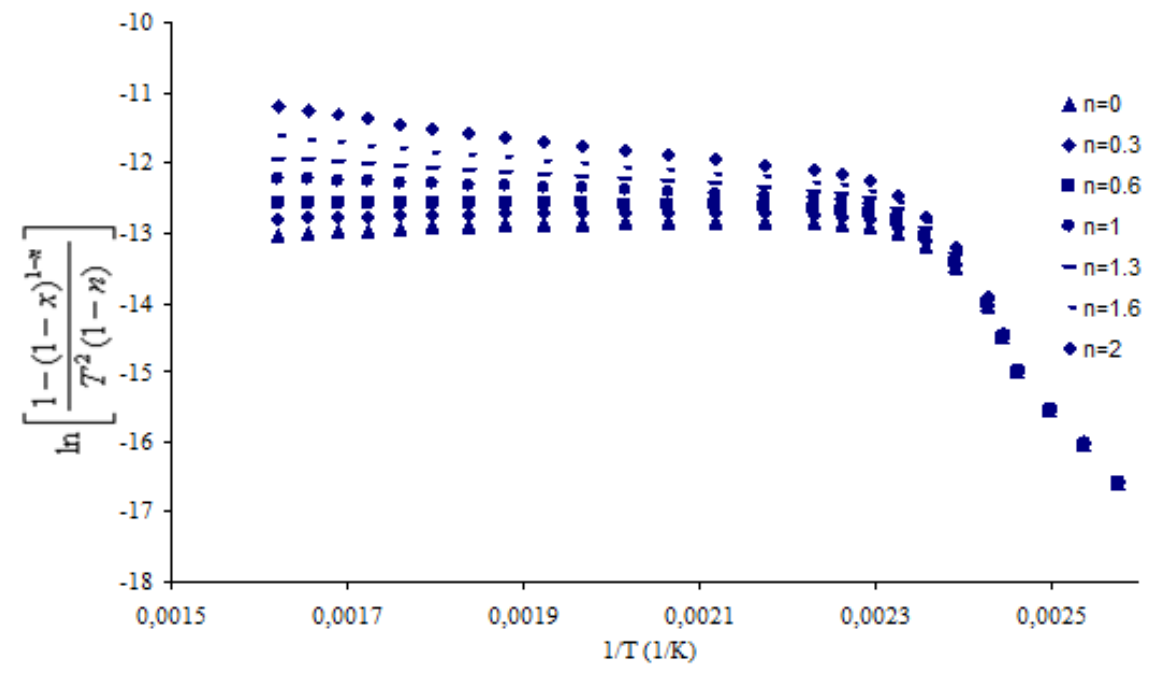

Figure 3. Plot of Eqs. 3s for different reaction order, $n$ at 5 K.min-1 heating rate

As seen in Figure 3, the dehydration reaction occurs in two steps. Each step was correlated for different order. The order producing the highest correlation coefficient was chosen to be the correct one. It was found that $0^{\text {th }}$ and $2^{\text {nd }}$ orders fit the experimental data best for step 1 and step 2 respectively. The lines corresponding to these orders at $5 \mathrm{~K} \cdot \mathrm{min}^{-1}$ heating rate is separately, shown in Figure 4. Step 1 is observed in the temperature range of $25-165^{\circ} \mathrm{C}$ and step 2 between 165 and $450^{\circ} \mathrm{C}$. Frequency factors and activation energies calculated from the intersection and slope of these lines are given in their Arrhenius form as follows;

$$
\begin{array}{ll}
\text { For step 1: } & k_{0}=5.37 \times 10^{15} \exp (-16141.5 / T) \\
\text { For step 2: } & k_{2}=1.4 \exp (-1575.6 / T)
\end{array}
$$

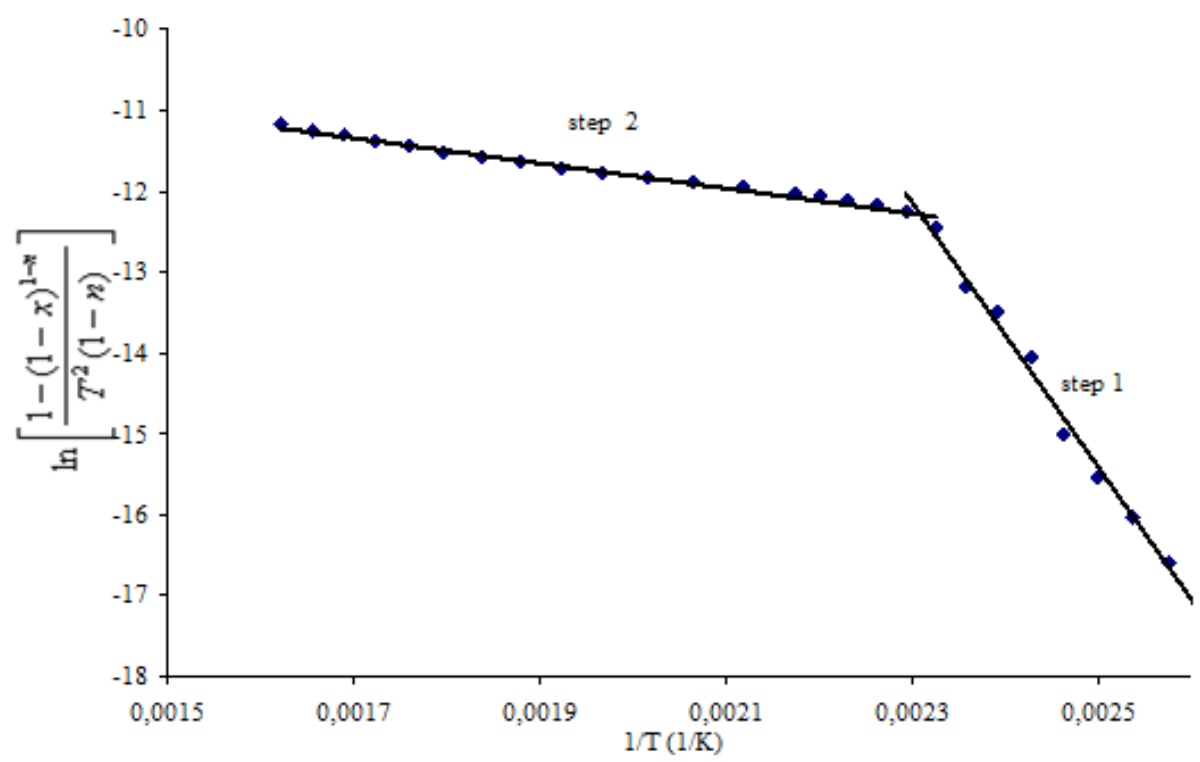

Figure 4. Plot of two step dehydration with zero and second order reaction respectively, at $5 \mathrm{~K} . \mathrm{min}^{-1}$ heating rate 
Figure 4 also shows that the first step occurs at temperatures lower than that of the second step. This is an expected result since the removal of the water molecules of crystallization is relatively easier than that of water molecules in ionic structure. That is, dehydration mechanism can be given as follows;

$$
\begin{gathered}
\mathrm{Na}_{2}\left(\mathrm{~B}_{4} \mathrm{O}_{5}(\mathrm{OH})_{4}\right) \cdot 3 \mathrm{H}_{2} \mathrm{O} \longrightarrow \mathrm{Na}_{2}\left(\mathrm{~B}_{4} \mathrm{O}_{5}(\mathrm{OH})_{4}\right) \cdot 0.75 \mathrm{H}_{2} \mathrm{O}+2.25 \mathrm{H}_{2} \mathrm{O} \\
\mathrm{Na}_{2}\left(\mathrm{~B}_{4} \mathrm{O}_{5}(\mathrm{OH})_{4}\right) \cdot 0.75 \mathrm{H}_{2} \mathrm{O} \longrightarrow \mathrm{Na}_{2} \mathrm{~B}_{4} \mathrm{O}_{7}+2.75 \mathrm{H}_{2} \mathrm{O}
\end{gathered}
$$

This result deviates by $25 \%$ from the general belief of the ratio of 3:2 [6]. It is attributed to the fact that the removal of the crystal water is getting more difficult as it decreases in the crystal. Therefore, it was concluded that 0.75 moles of crystal water behaves together with water in the ionic form.

Frequency factors and activation energies can also be calculated from Eq. 4 (Kissinger method) and 5s (Doyle method) by using DTA data. The results together with those calculated from Coats-Redfern are given in Table 2.

\begin{tabular}{|c|c|c|c|c|}
\hline \multirow[b]{3}{*}{$\mathrm{E}\left(\mathrm{kJ} . \mathrm{mol}^{-1}\right)$} & \multicolumn{4}{|c|}{ Method } \\
\hline & \multicolumn{2}{|c|}{ Coats and Redfern } & \multirow{2}{*}{$\begin{array}{l}\text { Kissinger } \\
162.0\end{array}$} & \multirow{2}{*}{$\begin{array}{l}\text { Doyle } \\
160.7\end{array}$} \\
\hline & $\begin{array}{l}\text { Step 1 } \\
\text { Step 2 }\end{array}$ & $\begin{array}{l}134.2 \\
13.1\end{array}$ & & \\
\hline $\mathbf{k}_{0}\left(\mathrm{~s}^{-1}\right)$ & $\begin{array}{l}\text { Step 1 } \\
\text { Step 2 }\end{array}$ & $\begin{array}{l}5.37 \times 10^{15} \\
1.4\end{array}$ & $1.123 \times 10^{18}$ & $1.054 \times 10^{18}$ \\
\hline
\end{tabular}

Table 2. Frequency factors and activation energies calculated by different methods

As seen in Table 2, total activation energy calculated from Coats-Redfern method is relatively lower than those calculated from Kissinger and Doyle method did. This discrepancy is compensated by relatively low frequency factor in Eqs. 6 and 7. Therefore, the results in Table 2 can be considered to be in a good agreement with each other.

\section{CONCLUSIONS}

Dehydration of BPH occurs in two steps. It was shown that 2.25 moles of crystal water removes in the temperature range between 382 and $433 \mathrm{~K}$ with zero order kinetics in the first step. The removing of the remaining water is completed at $733 \mathrm{~K}$ with a second order reaction in the second step. Arrhenius form of reaction rate constant for each step was also determined to be:

$$
\begin{array}{ll}
\text { For step 1: } & k_{0}=5.37 \times 10^{15} \exp (-16141.5 / T) \\
\text { For step 2: } & k_{2}=1.4 \exp (-1575.6 / T)
\end{array}
$$

\section{NOMENCLATURE}

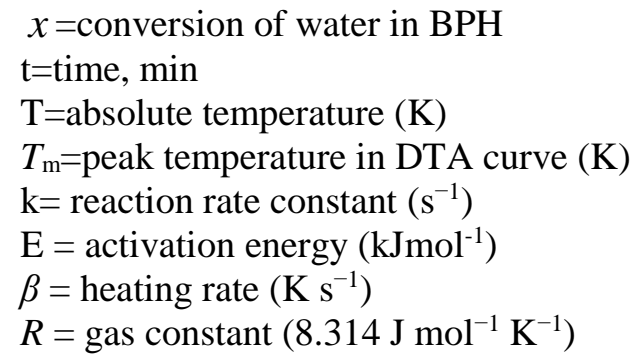


Akbay and Altıokka / Anadolu Univ. J. of Sci. and Technology A-Appl. Sci. and Eng. 18 (3) - 2017

\section{REFERENCES}

[1] Hubert M, Faber AJ. Effect of borate raw material choices on the batch reactions of Alkali-Lean borosilicate glasses. $76^{\text {th }}$ Conference on Glass Problems, 2016; 37(1): 43-56.

[2] Uwe EA, Boccaccini AR, Cook SG, Cheeseman, CR. Effect of borate addition on the sintered properties of pulverized fuel ash. Ceram Int 2007; 33: 993-999.

[3] Şahin Ö, Bulutcu AN. Evaluation of thermal decomposition kinetics of borax pentahydrate using genetic algorithm method by isothermal analysis. Turk J Chem 2003; 27: 197-207.

[4] Santos DMF, Sequeira CAC. Sodium borohydride as a fuel for the future, Renew Sustainable Energy Rev 2011; 15(8): 3980-4001.

[5] Şahin Ö, Bulutcu AN. Dehydration of borax pentahydrate behavior to anhydrous borax by multistage heating in a fluidized bed calcinator. Turk J Chem 2002; 26: 89-96.

[6] Kocakuşak S, Köroğlu JH, Ekinci E, Tolun R. Production of anhydrous borax using microwave heating. Ind Eng Chem Res 1995; 34: 881-885.

[7] Asensio MO, Yildirim M, Senberber F, Kipcak AS, Derun EM. Thermal dehydration kinetics and characterization of synthesized potassium borates. Res Chem Intermed 2016; 42(5): 4859-4878.

[8] Peng L, Qisui W, Xi L, Chaocan Z. Investigation of the states of water and $\mathrm{OH}$ groups on the surface of silica. Colloid Surf A 2009; 334: 112-115.

[9] Moura AO, Prado AGS. Effect of thermal dehydration and rehydration on Na-magadiite structure. Colloid Interf Sci 2009; 330: 392-398.

[10] Vlaev L, Nedelchev N, Gyurova K, Zagorcheva M. A comparative study of non-isothermal kinetics of decomposition of calcium oxalate monohydrate. J Anal Appl Pyrol 2008; 81(2):253262.

[11] Vecchio S, Di Rocco R, Ferragina C, Materazzi S. Thermal and kinetic study of dehydration and decomposition processes for copper intercalated gamma-zirconium and gamma-titanium phosphates. Thermochim Acta 2005; 435(2): 181-187.

[12] Ekmekyapar A, Baysar A, Künkül A. Dehydration kinetics of tincal and borax by thermal analysis. Ind Eng Chem Res 1997; 36(9): 3487-3490.

[13] Biyikoglu A, Yeksan E. Production of anhydrous borax borax pentahydrate. Int J Hydrogen Energ 2008; 33(23): 7103-7109.

[14] Waclawska I. Thermal decomposition of borax. Therm Anal Calorim 1995; 43: 261-269.

[15] Şahin Ö, Genli N, Özdemir M. New method for production anhydrous puffed borax. Chem Eng Process 2005; 44 (1):1-6.

[16] Coats AW, Redfern JP. Kinetic parameters from thermogravimetric data. Nature 1964; 20: 68-69.

[17] Doyle CD. Estimating isothermal life from thermogravimetric data. J Appl Polym Sci 1962; 6(24): 639-642. 